Research Article

\title{
Profit Sharing Mechanism of Large EPC Project considering the Behavior of Fairness Concern
}

\author{
Huimin Li, ${ }^{1,2,3}$ Lelin Lv, ${ }^{1}$ Xiaowei An ${ }^{(D)},{ }^{1,4}$ and Guanghua Dong ${ }^{1}$ \\ ${ }^{1}$ Department of Construction Engineering and Management, North China University of Water Resources and Electric Power, \\ Zhengzhou 450045, China \\ ${ }^{2}$ Henan Key Laboratory of Water Environment Simulation and Treatment, Zhengzhou 450045, China \\ ${ }^{3}$ Environment Governance and Ecological Restoration Academician Workstation of Henan Province, Zhengzhou 450002, China \\ ${ }^{4}$ Henan Water Valley Innovation Technology Research Institute Co., Ltd., Zhengzhou 450002, China
}

Correspondence should be addressed to Xiaowei An; axwwish@163.com

Received 21 September 2019; Revised 21 July 2020; Accepted 17 August 2020; Published 30 August 2020

Academic Editor: Hayri Baytan Ozmen

Copyright (c) 2020 Huimin Li et al. This is an open access article distributed under the Creative Commons Attribution License, which permits unrestricted use, distribution, and reproduction in any medium, provided the original work is properly cited.

\begin{abstract}
A large-scale engineering procurement and construction (EPC) project is often conducted by a joint venture. Many factors affect the success of cooperation among participating enterprises, such as trust and the degree of effort of both parties. The most important one is a rational profit sharing mechanism. Reasonable profit sharing mechanism concerns whether the advantages of the EPC model can be fully utilized. In this study, the proposed EPC project is undertaken by a joint venture integrating design and construction enterprises. Moreover, the profit sharing problem arises from the project optimization implemented by both parties. The fairness concern behavior of both parties is considered, and the profit sharing model for the EPC project is established on the basis of game theory. The effect of the fairness concern behavior of both parties on the EPC project optimization and its profit sharing is further analyzed by simulation analysis. The research findings show that the project optimization profit and its sharing are related to not only the efforts and cost coefficient but also the fairness concern behavior of both parties. The research results are conducive to the application of the EPC model in the field of construction engineering.
\end{abstract}

\section{Introduction}

Engineering procurement and construction (EPC) refer to a method used by a project owner when contracting the project design, construction, and procurement as a whole to a single contractor [1]. The most significant advantage of the EPC model is the integration of engineering design and construction, and the subject of contract responsibility is single, which has the advantages of reducing the engineering cost, improving the design constructability, and shortening the construction period [2-4]. Due to the many advantages mentioned above, the EPC model has developed rapidly in the engineering construction field in recent years and has become one of the most popular project delivery methods [5]. Especially with the development and application of BIM (building information modelling), the advantages of the EPC model will be significantly improved [6]. However, there are some problems with the implementation of the EPC model.
Effective management and system guarantee are the prerequisites for the advantages of the EPC model to be exerted. In engineering practice, a large-scale construction project is difficult to be undertaken by a single enterprise. A large-scale construction project is usually delivered by general contracting or joint venture, which is combined with several enterprises [7]. These enterprises cooperate to share risks and opportunities [8]. The reasonable sharing of the project profit is the foundation and critical issue for the friendly cooperation and maximum performance of participating parties, and it is related to whether the advantages of the EPC model can be fully utilized [2, 9]. Therefore, the establishment of a reasonable revenue sharing mechanism will contribute to the implementation and sustainable development of the EPC model.

The research findings of some scholars show that cooperation and effective resource integration is the key to the success of the EPC project [10], and the lack of effective 
cooperation often leads to its failure $[11,12]$. On the issue of profit distribution, some scholars have carried out some research. Parrod et al. [13] found that a reasonable profit sharing mechanism is the foundation and key to the cooperation of all subcontractors. Guan and $\mathrm{Hu}$ [14] studied the profit sharing problem of the joint venture project on the basis of contract and game theories. Zhang et al. [15] established a supply chain profit sharing model between general contractors and subcontractors based on an improved Shapley value method. Lv et al. [16] proposed the profit sharing method between the general contractor and subcontractor of a project based on profit sharing theory and Stackelberg game model. Wang and Zhang [17] considered the risks borne by the participants and introduced the profit sharing model of the EPC project by using the Shapley value method. Niu [7] considered three factors, namely, contribution, investment, and risk, and established the profit sharing method of the EPC project by integrating Shapley, fairness, and fuzzy analytic hierarchy process methods. An et al. [18] introduced the negotiation mechanism into the optimal profit sharing problem of the joint venture general contracting project and constructed the negotiation model to solve this problem. These studies can provide a reference for the EPC project profit sharing. However, none of them have considered the effect of the fairness concern behavior of subjects on project optimization and profit sharing. In the profit sharing process, the subjects will not only consider the distribution of their profit but also pay attention to the fairness of profit sharing [19].

In practice, all stakeholders in an EPC project pay great attention to their interests. They even set special conditions in the contracts to avoid damage to their interests. Therefore, all participants of the EPC project have fairness concern behavior. Fairness concern behavior refers to the fact that stakeholders not only pay attention to their interests in the process of profit distribution but also pay attention to whether the profit distribution among members is fair [19]. Various groups of researchers have worked with fairness concern behavior. Kahneman et al. [20] introduced fairness concern into economic management activities to analyze its effect on these activities. Fehr and Schmidt's research [21] found that when one party believes that the transaction is unfair or that their interests are not met, the transaction scheme or benefit distribution scheme is easily destroyed. Loch and $\mathrm{Wu}$ [22] found that the subjects' fairness concern behavior will reduce the overall system efficiency. Demirag et al. [23] and Katok and Pavlov [24] studied the effect of the subjects' fairness concern behavior on the supply chain profit sharing. Górecki and Bizon-Górecka [25] argued that a phenomenon of participants' fairness exists in the risk management of construction project and indicated that fairness can be treated as an essential factor in predicting the success of such projects [26]. An et al. [27] considered the subjects' fairness concern behavior and analyzed its influence on engineering design optimization and its profit sharing negotiation. Therefore, the subjects' fairness concern behavior has a direct influence on their decision making and should be considered in optimizing the profit sharing of the EPC project.
In the EPC project, the design and construction enterprises have different goals or interests. In order to achieve their goals and interests, all parties must consider the opponent's every possible action or plan, and try to choose the action or plan that is most beneficial or reasonable for them. Furthermore, the game theory is to study what actions the two parties will take during the game. In this study, the proposed EPC project is awarded to joint venture integrating design and construction enterprises. Their input, contribution, and fairness concern behavior are considered in the project optimization process. Furthermore, the profit sharing model is established on the basis of game theory. In this study, the optimal distribution proportion is determined; thus, the profit sharing mechanism of the EPC project is established. In addition, the effect of the fairness concern behavior of both parties on the EPC project optimization and profit sharing is further analyzed. Research results can provide support for the establishment of the EPC project revenue sharing mechanism and contribute to the application and sustainable development of the EPC model in the field of construction engineering.

\section{Problem Analysis}

Large-scale projects are challenging to be undertaken by a single enterprise. Therefore, this paper supposes that an EPC project is awarded to joint venture integrating design and construction enterprises, and adopts a lump sum contract. During the implementation process, the design and construction enterprises can optimize the project (design and construction plan optimization) to reduce the engineering cost and save on the construction cost to obtain considerable profit. For the EPC project contractor, profit can be composed of two parts: the fixed profit, which is the reasonable profit of the project under normal circumstances, and the project optimization profit, which is the cost saved by optimizing the project [14]. The fixed profit can be distributed following the contract, which is relatively simple. This study does not focus on the fixed profit but mainly analyzes the distribution of profit obtained through project optimization.

The rationality of the optimal profit sharing of the project is directly related to the enthusiasm of participants. If the optimal profit sharing of the project is reasonable, then the participating parties will have a high initiative to optimize the project to acquire additional benefits, and the cooperation among all parties can continue. Moreover, the advantages of the EPC model can be fully utilized. If the project optimization profit sharing is not reasonable, then the cooperation among the participants will be affected, and they will not have the initiative to optimize the project. The advantage of the EPC model is difficult to utilize. Figure 1 shows the profit sharing motivation model of the EPC project.

\section{Model Development}

\subsection{Basic Assumptions}

(1) This paper mainly studies the optimal profit sharing of a large-scale EPC project. Therefore, it is assumed 


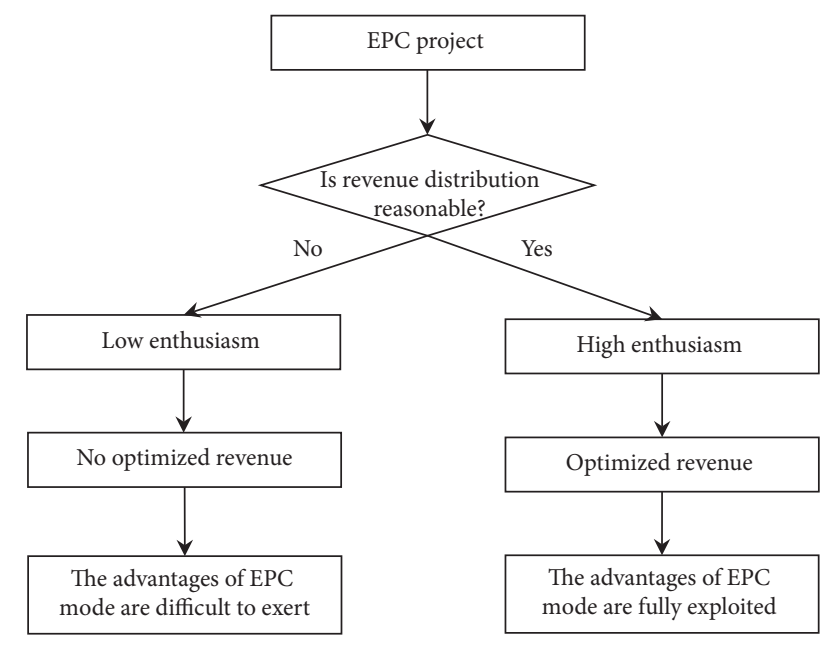

FIgURE 1: Profit sharing motivation model of the EPC project (selfdrawn).

that there is a particular optimization space for the project, and a certain profit can be obtained by optimizing the project.

(2) A large-scale EPC project is often undertaken by multiple participants, and the optimization of an engineering project is often completed by design and construction enterprises. Therefore, this paper only considers the profit sharing problem of the project optimization completed by the cooperation of the design and construction enterprises. The profit of project optimization is wholly shared between the two parties.

3.2. Profit Model. The EPC project often adopts the lump sum contract, and its contract price is set as $\mathrm{CP}$. The contract price $\mathrm{CP}$ can be divided into three parts: project construction cost $\mathrm{CC}$, fixed profit $\mathrm{FP}$, and project optimization profit OP:

$$
\mathrm{CP}=\mathrm{CC}+\mathrm{FP}+\mathrm{OP} .
$$

The project optimization profit OP is part of the contract price $\mathrm{CP}$, which can be set as follows:

$$
\mathrm{OP}=\eta \varphi \mathrm{CP} \text {. }
$$

In equation (2), $\varphi$ is the maximum yield factor that can be achieved by optimizing the project, $\varphi \in(0,1) . \varphi$ is related to factors such as engineering complexity, geological conditions, and design depth. $\eta$ denotes the degree of engineering optimization implementation, $\eta \in[0,1]$, that is, the degree of project optimization that can be achieved through the efforts of both parties. The realization degree of project optimization $\eta$ is related to the effort level and effectiveness of the design and construction enterprises:

$$
\eta=f\left(\chi_{1}, \beta_{1}, \chi_{2}, \beta_{2}\right) .
$$

In equation (3), $\chi_{1}$ and $\chi_{2}$ indicate the effort levels of the design and construction enterprises to implement the project optimization matters, respectively. For simplicity, $\chi_{1}$ and $\chi_{2}$ can be set as one-dimensional continuous variables, expressed as real numbers between 0 and 1; i.e., $\chi_{1} \in[0,1]$ and $\chi_{2} \in[0,1]$. The larger $\chi_{1}$ and $\chi_{2}$, the more efforts the two parties made to optimize the project; $\beta_{1}$ and $\beta_{2}$ represent the utility coefficients of the efforts of the design and construction enterprises, respectively. Similarly, set $\beta_{1} \in[0,1]$ and $\beta_{2} \in[0,1]$. The larger $\beta_{1}$ and $\beta_{2}$, the higher the efficiency of the two's efforts to optimize the project.

$\eta$ is positively related to the efforts of both parties. Therefore, $f\left(\chi_{1}, \beta_{1}, \chi_{2}, \beta_{2}\right)$ should be a strictly monotone increasing function of $\chi_{i}$, namely, $\left(\partial f / \partial \chi_{i}\right)>0$, where $i=1,2$, and should satisfy $\eta \in[0,1]$; then, the following can be assumed:

$$
\eta=\frac{1}{2}\left(\beta_{1} \chi_{1}+\beta_{2} \chi_{2}+\xi\right) \text {. }
$$

In equation (4), $\xi$ is a random disturbance variable, which is assumed to be normally distributed; namely, $\xi \sim N\left(0, \sigma^{2}\right)$. Therefore, the project optimization profit OP can be expressed as

$$
\mathrm{OP}=\frac{1}{2} \varphi \mathrm{CP}\left(\beta_{1} \chi_{1}+\beta_{2} \chi_{2}+\xi\right) .
$$

Project optimization can create profit, whereas the project optimization process requires both parties to input certain costs. The project optimization cost is set as OC:

$$
\mathrm{OC}=\mathrm{OC}_{1}+\mathrm{OC}_{2}
$$

In equation (6), $\mathrm{OC}_{1}$ and $\mathrm{OC}_{2}$ represent the costs of the design and construction enterprises, respectively.

By subtracting the project optimization cost from the project optimization profit, the project optimization net profit NP can be obtained as

$$
\mathrm{NP}=\mathrm{OP}-\mathrm{OC} .
$$

By substituting OP and OC into equation (6), the following can be obtained:

$$
\mathrm{NP}=\frac{1}{2} \varphi \mathrm{CP}\left(\beta_{1} \chi_{1}+\beta_{2} \chi_{2}+\xi\right)-\mathrm{OC}_{1}-\mathrm{OC}_{2} .
$$

3.3. Optimal Profit Sharing Model. The profit obtained through project optimization is shared between the design and construction enterprises. It is supposed that the design enterprise can acquire part $\lambda$ ( $\lambda$ is the profit sharing coefficient, and $0<\lambda<1$ ) of the total profit. The construction enterprise can obtain part $1-\lambda$ of the total profit. The cost is subtracted from the profits earned by both parties; then, the net profits obtained by both parties due to project optimization are as follows:

$$
\begin{aligned}
& \mathrm{NP}_{1}=\lambda \mathrm{OP}-\mathrm{OC}_{1}, \\
& \mathrm{NP}_{2}=(1-\lambda) \mathrm{OP}-\mathrm{OC}_{2} .
\end{aligned}
$$

In equation (9), $\mathrm{NP}_{1}$ is the net project optimization profit of the design enterprise; in equation (10), $\mathrm{NP}_{2}$ denotes the net project optimization profit of the construction enterprise. 
The cost of both parties in the project optimization process mainly consists of two parts: the tangible cost of project optimization (e.g., the input of capital or equipment and the resource distribution cost paid by the construction enterprise for implementing the optimization plan) and the knowledge cost. Project optimization is a highly technical task that requires the input of expertise from both parties. The acquisition and accumulation of professional knowledge also require costs, which can be considered as the knowledge cost of both parties. Let $\mathrm{OC}_{01}$ and $\mathrm{OC}_{02}$ represent the tangible costs of the design and construction enterprises to optimize the project, respectively. $\mathrm{KC}_{1}$ and $\mathrm{KC}_{2}$ denote the knowledge cost invested by both parties in the optimization project, respectively:

$$
\begin{aligned}
& \mathrm{OC}_{1}=\mathrm{OC}_{01}+\mathrm{KC}_{1}, \\
& \mathrm{OC}_{2}=\mathrm{OC}_{02}+\mathrm{KC}_{2} .
\end{aligned}
$$

In the project optimization process, the tangible cost of both parties can be directly observed and measured. In contrast, the knowledge input cannot be directly measured, but the knowledge cost can be measured by the cost coefficient and effort level of each party's knowledge input $[14,18]$. Therefore,

$$
\mathrm{KC}_{i}=f\left(\alpha_{i}, \chi_{i}\right), \quad i=1,2 .
$$

In equation (13), $\alpha_{i}$ is the knowledge cost coefficient, $\alpha_{i}>0(i=1,2)$, which can be obtained by assessment or experience.

The knowledge cost is proportional to the effort of all parties; that is, $f\left(\alpha_{i}, \chi_{i}\right)$ is the increasing function of effort level $\chi_{i}$, so $\left(\partial \mathrm{KC}_{i} / \partial \chi_{i}\right)>0$; at the same time, the marginal cost of knowledge is increasing; that is, $\left(\partial^{2} \mathrm{KC}_{i} / \partial^{2} \chi_{i}\right)>0$. Therefore, the following is assumed [27]:

$$
\mathrm{KC}_{i}=\frac{1}{2} \alpha_{i} \chi_{i}^{2}, \quad i=1,2 .
$$

Then,

$$
\begin{aligned}
& \mathrm{OC}_{1}=\frac{1}{2} \alpha_{1} \chi_{1}^{2}+\mathrm{OC}_{01}, \\
& \mathrm{OC}_{2}=\frac{1}{2} \alpha_{2} \chi_{2}^{2}+\mathrm{OC}_{02} .
\end{aligned}
$$

By substituting $\mathrm{CP}, \mathrm{OC}_{1}$, and $\mathrm{OC}_{2}$ into equations (8)-(10), respectively, the following can be obtained:

$$
\begin{aligned}
& \mathrm{NP}_{1}=\frac{1}{2} \lambda \varphi \mathrm{CP}\left(\beta_{1} \chi_{1}+\beta_{2} \chi_{2}+\xi\right)-\frac{1}{2} \alpha_{1} \chi_{1}^{2}-\mathrm{OC}_{01}, \\
& \mathrm{NP}_{2}=\frac{1}{2}(1-\lambda) \varphi \mathrm{CP}\left(\beta_{1} \chi_{1}+\beta_{2} \chi_{2}+\xi\right)-\frac{1}{2} \alpha_{2} \chi_{2}^{2}-\mathrm{OC}_{02}
\end{aligned}
$$

$$
\begin{aligned}
\mathrm{NP}= & \frac{1}{2} \varphi \mathrm{CP}\left(\beta_{1} \chi_{1}+\beta_{2} \chi_{2}+\xi\right)-\frac{1}{2} \alpha_{1} \chi_{1}^{2}-\mathrm{OC}_{01}-\frac{1}{2} \alpha_{2} \chi_{2}^{2} \\
& -\mathrm{OC}_{02} .
\end{aligned}
$$

3.4. Fairness Concern Function. Given the subject's fair preference, the effectiveness of the participant can be from absolute profit utility, pride preference utility, and jealousy preference utility. The absolute profit utility is pure profit, the pride preference utility is positive utility, and the jealousy preference utility is negative utility [28]. Therefore, considering the fairness concern of both parties, the utilities of the design and construction enterprises can be, respectively, expressed as [29]

$$
\begin{aligned}
S\left(\mathrm{NP}_{1}\right)= & \mathrm{NP}_{1}+k_{1}^{\prime} \max \left[\left(\mathrm{NP}_{1}-\mathrm{NP}_{2}\right), 0\right] \\
& -k_{1}^{\prime \prime} \max \left[\left(\mathrm{NP}_{2}-\mathrm{NP}_{1}\right), 0\right], \\
S\left(\mathrm{NP}_{2}\right)= & \mathrm{NP}_{2}+k_{2}^{\prime} \max \left[\left(\mathrm{NP}_{2}-\mathrm{NP}_{1}\right), 0\right] \\
& -k_{2}^{\prime \prime} \max \left[\left(\mathrm{NP}_{1}-\mathrm{NP}_{2}\right), 0\right],
\end{aligned}
$$

In equations (19) and (20), $k_{1}^{\prime}$ and $k_{1}^{\prime \prime}$ are the pride and jealousy preference coefficients of the design enterprise, respectively, and $k_{1}^{\prime} \geq 0, k_{1}^{\prime \prime} \geq 0 . k_{2}^{\prime}$ and $k_{2}^{\prime \prime}$ represent the pride and jealousy preference coefficients of the construction enterprise, respectively, and $k_{2}^{\prime} \geq 0, k_{2}^{\prime \prime} \geq 0$. For the convenience of calculation, let $k_{1}=k_{1}^{\prime}=k_{1}^{\prime \prime}$ and $k_{2}=k_{2}^{\prime}=k_{2}^{\prime \prime}$; these can be used to uniformly express the fairness concern coefficients of the design and construction enterprises, respectively, and $k_{1} \geq 0$, $k_{2} \geq 0$ [28]. The higher the fairness concern coefficient is, the higher the fairness concern degree is, which indicates that further attention should be paid to the fairness of their profit sharing. When the fairness concern behavior of both parties is considered, their utility can be expressed as

$$
\begin{aligned}
& S\left(\mathrm{NP}_{1}\right)=\mathrm{NP}_{1}-k_{1}\left(\mathrm{NP}_{2}-\mathrm{NP}_{1}\right) \\
& S\left(\mathrm{NP}_{2}\right)=\mathrm{NP}_{2}-k_{2}\left(\mathrm{NP}_{1}-\mathrm{NP}_{2}\right) .
\end{aligned}
$$

By substituting $\mathrm{NP}_{1}$ and $\mathrm{NP}_{2}$ into equations (21) and (22), respectively,

$$
\begin{aligned}
S\left(\mathrm{NP}_{1}\right)= & \frac{1}{2} \lambda \varphi \mathrm{CP}\left(\beta_{1} \chi_{1}+\beta_{2} \chi_{2}+\xi\right)-\frac{1}{2} \alpha_{1} \chi_{1}^{2}-\mathrm{OC}_{01} \\
& -k_{1}\left[\frac{1}{2}(1-2 \lambda) \varphi \mathrm{CP}\left(\beta_{1} \chi_{1}+\beta_{2} \chi_{2}+\xi\right)-\frac{1}{2} \alpha_{2} \chi_{2}^{2}\right. \\
& \left.-\mathrm{OC}_{02}+\frac{1}{2} \alpha_{1} \chi_{1}^{2}+\mathrm{OC}_{01}\right]
\end{aligned}
$$

$$
\begin{aligned}
S\left(\mathrm{NP}_{2}\right)= & \frac{1}{2}(1-\lambda) \varphi \mathrm{CP}\left(\beta_{1} \chi_{1}+\beta_{2} \chi_{2}+\xi\right)-\frac{1}{2} \alpha_{2} \chi_{2}^{2}-\mathrm{OC}_{02} \\
& +k_{2}\left[\frac{1}{2}(1-2 \lambda) \varphi \mathrm{CP}\left(\beta_{1} \chi_{1}+\beta_{2} \chi_{2}+\xi\right)-\frac{1}{2} \alpha_{2} \chi_{2}^{2}\right. \\
& \left.-\mathrm{OC}_{02}+\frac{1}{2} \alpha_{1} \chi_{1}^{2}+O C_{01}\right] .
\end{aligned}
$$

The subject fairness preference is only the fairness perception of its own. The fairness preference will affect the effort level, profit sharing, and expected utility of both parties. But, it will not affect the actual project optimization profit and actual profit obtained by both parties. 
3.5. Model Solving. Equations (23) and (24) show that the profit of both parties is related to their respective efforts. Striving for the partial derivative of equation (23) with respect to $\chi_{1}$ and of equation (24) with respect to $\chi_{2}$, and letting $\left(\partial \mathrm{NP}_{1} / \partial \chi_{1}\right)=0, \quad\left(\partial \mathrm{NP}_{2} / \partial \chi_{2}\right)=0$, the following can be obtained:

$$
\begin{aligned}
& \chi_{1}^{*}=\frac{\left[\lambda+(2 \lambda-1) k_{1}\right] \varphi \mathrm{CP} \beta_{1}}{2\left(1+k_{1}\right) \alpha_{1}}, \\
& \chi_{2}^{*}=\frac{\left[(1-\lambda)+(1-2 \lambda) k_{2}\right] \varphi \mathrm{CP} \beta_{2}}{2\left(1+k_{2}\right) \alpha_{2}} .
\end{aligned}
$$

Then, $\chi_{1}^{*}$ indicates the optimal effort degree of the design enterprise. $\chi_{2}^{*}$ refers to the optimal effort degree of the construction enterprise.

Equation (25) indicates that the optimal effort degree of the design enterprise $\chi_{1}^{*}$ is directly proportional to its effort utility coefficient $\beta_{1}$, the profit sharing coefficient $\lambda$, and the maximum profit $\varphi \mathrm{CP}$ that can be realized by project optimization. Moreover, $\chi_{1}^{*}$ is inversely proportional to its own effort cost coefficient $\alpha_{1}$ and related to its fairness preference $k_{1}$. Similarly, equation (26) presents that the optimal effort degree of the construction enterprise $\chi_{2}^{*}$ is directly proportional to its effort utility coefficient $\beta_{2}$ and the maximum profit that the project optimization can achieve $\varphi \mathrm{CP}$. And $\chi_{2}^{*}$ is inversely proportional to its effort cost coefficient $\alpha_{2}$ and the proportion of profit sharing $\lambda$ that the design enterprise can obtain and related to its fairness preference $k_{2}$. (18),

By substituting the values of $\chi_{1}^{*}$ and $\chi_{2}^{*}$ into equation

$$
\begin{aligned}
\mathrm{NP}= & \frac{1}{2} \varphi \mathrm{CP}\left\{\frac{\left[\lambda+(2 \lambda-1) k_{1}\right] \varphi \mathrm{CP} \beta_{1}^{2}}{2\left(1+k_{1}\right) \alpha_{1}}\right. \\
& \left.+\frac{\left[(1-\lambda)-(2 \lambda-1) k_{2}\right] \varphi \mathrm{CP} \beta_{2}^{2}}{2\left(1+k_{2}\right) \alpha_{2}}+\xi\right\} \\
& -\frac{\left[\lambda+(2 \lambda-1) k_{1}\right]^{2} \varphi^{2} \mathrm{CP}^{2} \beta_{1}^{2}}{8\left(1+k_{1}\right)^{2} \alpha_{1}}-\mathrm{OC}_{01} \\
& -\frac{\left[(1-\lambda)-(2 \lambda-1) k_{2}\right]^{2} \varphi^{2} \mathrm{CP}^{2} \beta_{2}^{2}}{8\left(1+k_{2}\right)^{2} \alpha_{2}}-\mathrm{OC}_{02} .
\end{aligned}
$$

The project optimization profit NP has a maximum value of $\lambda$. Therefore, the partial derivative of both sides of equation (27) with respect to $\lambda$ can be written:

$$
\begin{aligned}
\frac{\partial \mathrm{NP}}{\partial \lambda}= & \frac{\left(1+2 k_{1}\right) \varphi^{2} \mathrm{CP}^{2} \beta_{1}^{2}}{4\left(1+k_{1}\right) \alpha_{1}}-\frac{\left(2 k_{2}+1\right) \varphi^{2} \mathrm{CP}^{2} \beta_{2}^{2}}{4\left(1+k_{2}\right) \alpha_{2}} \\
& -\frac{\left(1+2 k_{1}\right)\left[\lambda+(2 \lambda-1) k_{1}\right] \varphi^{2} \mathrm{CP}^{2} \beta_{1}^{2}}{4\left(1+k_{1}\right)^{2} \alpha_{1}} \\
& +\frac{\left(2 k_{2}+1\right)\left[(1-\lambda)+(2 \lambda-1) k_{2}\right] \varphi^{2} \mathrm{CP}^{2} \beta_{2}^{2}}{4\left(1+k_{2}\right)^{2} \alpha_{2}} .
\end{aligned}
$$

Let $(\partial \mathrm{NP} / \partial \lambda)=0$; when the project profit is maximized, the optimal profit sharing coefficient $\lambda^{*}$ can be obtained:

$$
\lambda^{*}=\frac{\left(1+2 k_{1}\right)^{2}\left(1+k_{2}\right)^{2} \alpha_{2} \beta_{1}^{2}-2 k_{2}\left(1+k_{1}\right)^{2}\left(1+2 k_{2}\right) \alpha_{1} \beta_{2}^{2}}{\left(1+k_{2}\right)^{2}\left(1+2 k_{1}\right)^{2} \alpha_{2} \beta_{1}^{2}-\left(1+k_{1}\right)^{2}\left(4 k_{2}^{2}-1\right) \alpha_{1} \beta_{2}^{2}} .
$$

Equation (29) shows that the optimal profit sharing coefficient $\lambda^{*}$ is related to the knowledge cost utility coefficient, cost coefficient, and fairness preference degree of both parties. Thus, the design enterprise can obtain $\lambda^{*}$ of the total project optimization profit, whereas the construction enterprise can acquire $1-\lambda^{*}$ of the total project optimization profit.

\section{Simulation Analysis}

4.1. Basic Parameters. The construction project is delivered by the model of EPC and is awarded to a joint venture with the lump sum contract. The contract value is $\mathrm{CP}=1.337$ billion yuan. The maximum cost reduction amount that can be achieved through project optimization is assumed to account for $\varphi=2 \%$ of the contract value. The tangible cost required by the design enterprise is $\mathrm{OC}_{01}=921,800$ yuan, whereas the tangible cost required by the construction enterprise is $\mathrm{OC}_{02}=1,599,600$ yuan. The cost coefficients of the knowledge input of design and construction firms are $\alpha_{1}=7$ million yuan and $\alpha_{2}=3.5$ million yuan, respectively. The efforts utility coefficients of design and construction firms are $\beta_{1}=0.85$ and $\beta_{2}=0.65$, respectively.

4.2. Result Analysis. On the basis of the profit sharing mechanism established previously and the fairness preference of both parties, their optimal effort level, profit sharing coefficient, and project optimization profit can be obtained under different fairness concerns through calculation, as shown in Table 1.

Table 1 shows that the fairness concern degree of both parties influences their efforts $\chi_{1}^{*}$ and $\chi_{2}^{*}$, profit sharing coefficient $\lambda^{*}$, total project optimization profit NP, and net profits $\mathrm{NP}_{1}$ and $\mathrm{NP}_{2}$.

4.2.1. Effect of the Fairness Concern Behavior of Both Parties on Their Efforts. By using MATLAB, the data in Table 1 can be used to draw the fairness concern behavior and efforts of both parties $\chi_{1}^{*}, \chi_{2}^{*}$, as shown in Figures 2 and 3. In Figures 2 and 3 , the vertical axis $k_{1}$ and horizontal axis $k_{2}$ are the fairness concern degrees of the design and construction enterprises, respectively, and the vertical axes $\chi_{1}^{*}$ and $\chi_{2}^{*}$ are the efforts of both parties.

Figure 2 shows that when the fairness concern degree of the construction enterprise is constant, as the design enterprise's fairness concern degree increases, the design enterprise's effort degree will gradually increase. That is, the higher the degree of fairness is concerned by the design enterprise, the higher its effort degree is. However, when the design enterprise's fairness concern degree is certain, its effort degree will gradually decrease with the increasing of the construction enterprise's fairness concern degree. That is, the higher the degree of fairness is concerned by the 
TABLE 1: Numerical simulation under different fairness preference.

\begin{tabular}{|c|c|c|c|c|c|c|c|}
\hline$k_{1}$ & $k_{2}$ & $\chi_{1}^{*}$ & $\chi_{2}^{*}$ & $\lambda^{*}$ & NP & $\mathrm{NP}_{1}$ & $\mathrm{NP}_{2}$ \\
\hline \multirow{5}{*}{0} & 0 & 0.954 & 1.000 & 0.588 & 1207.6 & 737.1 & 470.5 \\
\hline & 0.25 & 0.805 & 1.000 & 0.496 & 1130.2 & 566.0 & 564.2 \\
\hline & 0.5 & 0.611 & 1.000 & 0.376 & 1005.5 & 365.4 & 640.1 \\
\hline & 0.75 & 0.320 & 1.000 & 0.197 & 769.9 & 115.1 & 654.8 \\
\hline & 1.0 & -0.180 & 1.000 & -0.111 & 225.7 & -177.3 & 403.0 \\
\hline \multirow{5}{*}{0.25} & 0 & 0.985 & 0.814 & 0.672 & 1119.0 & 796.3 & 322.7 \\
\hline & 0.25 & 0.8 & 0.633 & 0.621 & 959.5 & 599.7 & 359.8 \\
\hline & 0.5 & 0.78 & 0.606 & 0.567 & 883.8 & 496.0 & 387.7 \\
\hline & 0.75 & 0.6 & 0.697 & 0.50 & 863.7 & 437.6 & 426.1 \\
\hline & 1.0 & 0.501 & 0.904 & 0.424 & 872.1 & 394.5 & 477.7 \\
\hline \multirow{5}{*}{0.5} & 0 & 1.000 & 0.703 & 0.717 & 1058.6 & 810.5 & 248.1 \\
\hline & 0.25 & 0.934 & 0.453 & 0.681 & 861.4 & 593.8 & 267.6 \\
\hline & 0.5 & 0.864 & 0.334 & 0.649 & 739.2 & 472.3 & 266.9 \\
\hline & 0.75 & 0.7 & 0.298 & 0.61 & 672.1 & 402.3 & 269.8 \\
\hline & 1.0 & 0.713 & 0.325 & 0.580 & 644.1 & 363.0 & 281.1 \\
\hline \multirow{5}{*}{0.75} & 0 & 1.000 & 0.635 & 0.744 & 1015.8 & 814.3 & 201.5 \\
\hline & 0.25 & 0.966 & 0.348 & 0.717 & 800.2 & 584.5 & 215.7 \\
\hline & 0.5 & 0.915 & 0.184 & 0.694 & 648.7 & 447.9 & 200.7 \\
\hline & 0.75 & & 0.0 & & $54 \mathrm{C}$ & 363.2 & 186.6 \\
\hline & 1.0 & 0.818 & 0.053 & 0.653 & 488.4 & 310.0 & 178.4 \\
\hline \multirow{5}{*}{1.0} & 0 & 1.000 & 0.590 & 0.762 & 986.3 & 815.1 & 171.2 \\
\hline & 0.25 & 0.989 & 0.279 & 0.740 & 758.7 & 576.3 & 182.4 \\
\hline & 0.5 & 0.948 & 0.090 & 0.723 & 587.8 & 428.6 & 159.1 \\
\hline & 0.75 & & -0.029 & & 468.1 & 332.9 & 135.2 \\
\hline & 1.0 & 0.880 & -0.104 & 0.695 & 384.3 & 268.5 & 115. \\
\hline
\end{tabular}

Note. The units of $\mathrm{NP}, \mathrm{NP}_{1}$, and $\mathrm{NP}_{2}$ in the table are 10 thousand yuan.

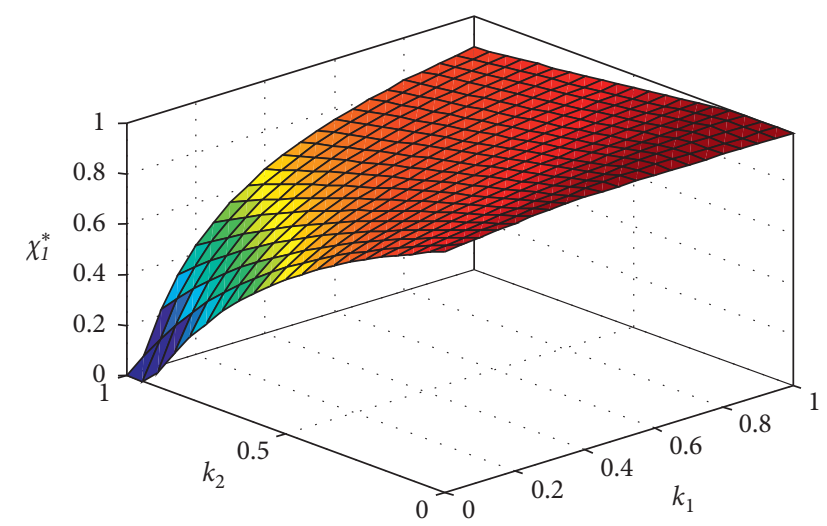

FIGURE 2: Relationship between the effort degree of the design enterprise $\chi_{1}^{*}$ and the fairness concern behavior of both parties.

construction enterprise, the lower the effort degree of the design enterprise is.

Figure 3 shows that when the construction enterprise is concerned about fairness to a certain extent, its effort degree will gradually decrease with the increasing of the design enterprise's fairness concern degree. That is, the higher the degree of fairness is concerned by the design enterprise, the lower the effort degree of the construction enterprise is. The design enterprise is less concerned about fairness than the construction enterprise (such as $k_{1}=0.25$ ). To a certain extent, the construction enterprise's effort degree first decreases and then increases with the increase of its fairness

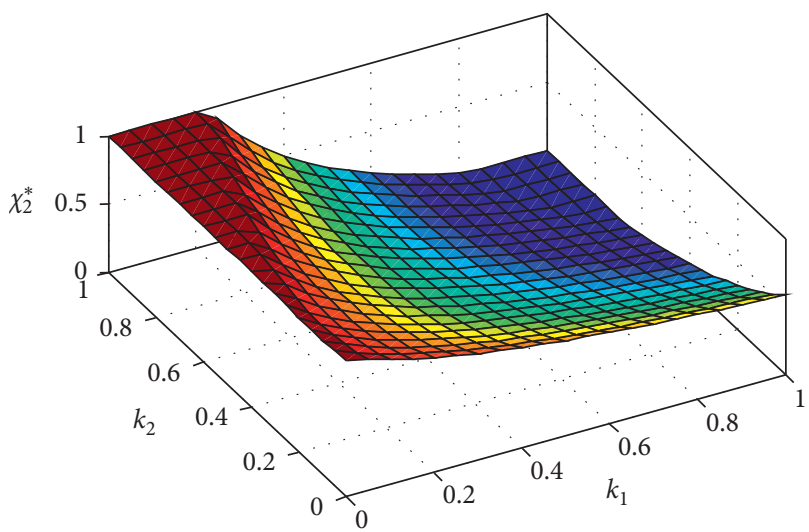

Figure 3: Relationship between the effort degree of the construction enterprise $\chi_{2}^{*}$ and the fairness concern behavior of both parties.

concern degree. However, the design enterprise is more concerned about fairness than the construction enterprise (such as $k_{1}=0.75$ ). The construction enterprise's effort gradually decreases with the increase of its fairness concern.

\subsubsection{Effect of the Fairness Concern Behavior of Both Parties} on the Profit Sharing Coefficient and the Total Profit from Project Optimization. The data in Table 1 can be used by MATLAB to illustrate the relationship between the profit sharing coefficient $\lambda^{*}$ and project optimization total profit $\mathrm{NP}$ and the fairness concern behavior of both parties, as shown in Figures 4 and 5. In Figures 4 and 5, the vertical axis $k_{1}$ and horizontal axis $k_{2}$ are the fairness concern degrees of the design and construction enterprises, respectively, and the vertical axis $\lambda^{*}$ represents the profit sharing coefficient. The vertical axis NP denotes the total project optimization profit.

Figure 4 illustrates that when the construction enterprise is concerned about fairness to a certain extent, the profit sharing coefficient will gradually increase with the increasing of the design enterprise's fairness concern degree. That is, the higher the degree of fairness is concerned by the design enterprise, the higher the profit sharing coefficient is. As the design enterprise can obtain part $\lambda^{*}$ of the total profit, the larger the value of the profit sharing coefficient is, the more profit the design enterprise will get. When the design enterprise has a certain level of fairness concern, the profit sharing coefficient will gradually decrease with the increasing of the construction enterprise's fairness concern degree. That is, the higher the degree of fairness concerned by construction enterprises is, the smaller the profit sharing coefficient is, the smaller the profit sharing coefficient is. As the construction enterprise obtains part $1-\lambda^{*}$ of the total profit, the smaller the value of the profit sharing coefficient $\lambda^{*}$ is, the more profit the construction enterprise will get. Therefore, when the other party has a certain level of fairness concern, a high level of fairness concern of both parties will be beneficial to them.

Figure 5 illustrates that when the design enterprise's fairness concern degree is at a certain level, the total project 


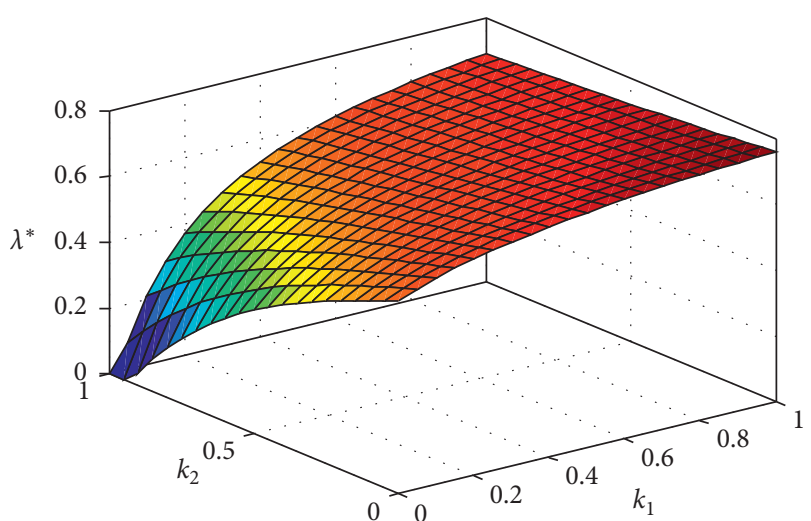

FIgURE 4: Relationship between the profit sharing coefficient $\lambda^{*}$ and fairness concern behavior of both parties.

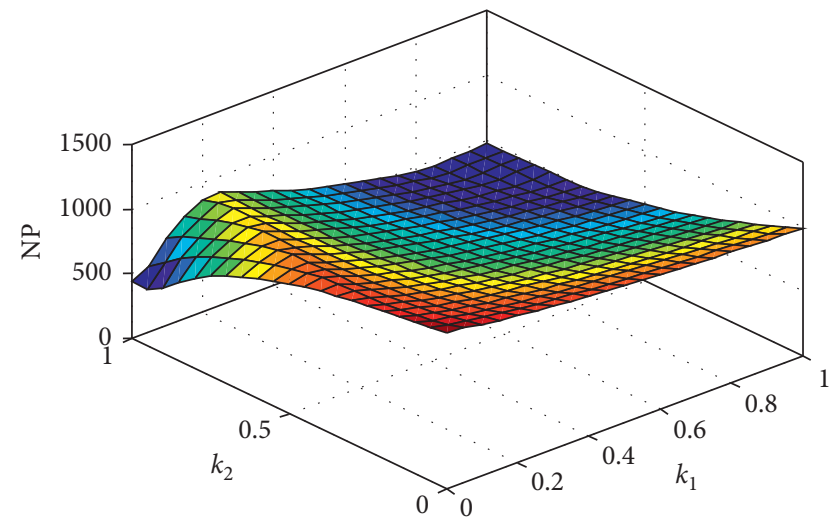

Figure 5: Relationship between the total project optimization profit NP and fairness concern behavior of both parties.

optimization profit will gradually decrease with the increase of the construction enterprise's fairness concern degree. That is, the higher the degree of fairness is concerned by the construction enterprise, the smaller the total profit of project optimization is. Under the low fairness concern degree of the construction enterprise (such as $k_{2}=0.25$ ), the total project optimization profit will decrease continuously with the increase of the fairness concern of the design enterprise. That is, the higher the degree of fairness is concerned by the design enterprise, the smaller the total profit of project optimization is. However, under the high fairness concern degree of the construction enterprise (such as $k_{1}=1$ ), the total project optimization profit increases first. It then decreases gradually with the increase of the fairness concern of the design enterprise. Therefore, in general, with the increase of fairness concerns of design and construction enterprises, the total profit of optimization will decrease.

4.2.3. Effect of Fairness Concern on the Net Profit of Both Parties. The data in Table 1 can be used by MATLAB to draw the relationship between the net profits $\mathrm{NP}_{1}, \mathrm{NP}_{2}$ and fairness concern behavior of both parties, as shown in Figures 6 and 7. In Figures 6 and 7, the vertical axis $k_{1}$ and horizontal axis $k_{2}$ are the fairness concern degrees of the design and construction enterprises, respectively, and $\mathrm{NP}_{1}$ and $\mathrm{NP}_{2}$ in the vertical axis represent the net project optimization profits of both parties, respectively.

Figure 6 shows that when the construction enterprise is concerned about fairness to a certain extent, the net profit obtained by the design enterprise will gradually increase with the increasing of the design enterprise's fairness concern degree. However, when the fairness concern degree of the design enterprise is at a certain level, the net profit that the design enterprise can obtain will gradually decrease with the increase of the fairness concern degree of the construction enterprise. Therefore, from the perspective of maximizing their profit, the more the design enterprise concerns about fairness, the more beneficial the design enterprise can get. Furthermore, the more construction enterprise concerns fairness, and the less profit design enterprise would get.

Figure 7 shows that when the construction enterprise has a certain fairness concern degree, the net profit that the construction enterprise can obtain will decrease with the increase of the design enterprise's fairness concern degree. Under a low fairness concern degree of the design enterprise (such as $k_{1}=0.25$ ), the net profit that the construction enterprise can obtain will increase with the increase of its fairness concern degree. However, under a relatively high level of fairness concern of the design enterprise (such as $k_{1}=1$ ), the net profit that the construction enterprise can obtain will decrease with the increase of its fairness concern degree. Therefore, in general, from the perspective of maximizing their interests, the fairness concern degree of construction enterprises should not be too high.

In addition, the calculation results in Table 1 show that, with the increasing concern for the fairness of both parties, negative values (italicized in the table) will appear, which is unreasonable. This situation indicates that one party is unwilling to participate in the project optimization, and the optimization cannot be implemented. Therefore, in general, when the other party has a certain fairness concern degree, its profit will increase with the increase of its fairness concern degree. However, at the same time, another party's profit will decrease, and the total project optimization profit will also decrease. When both parties have excessively high concerns about fairness, the profit sharing of project optimization is difficult to achieve, thereby hindering its implementation. Therefore, from the perspective of the implementation of the project optimization, the fairness concern degree of the design and construction enterprises should not be too high. Otherwise, it will affect the implementation of project optimization, and the advantages of the EPC model will also be challenging to realize.

\section{Conclusions}

The EPC model has been developing rapidly in the field of construction engineering in recent years. Several enterprises often complete a large-scale EPC project through general contracting or joint venture. Therefore, a reasonable profit sharing mechanism is the foundation of the cooperation among all parties involved. This case is related to the full 


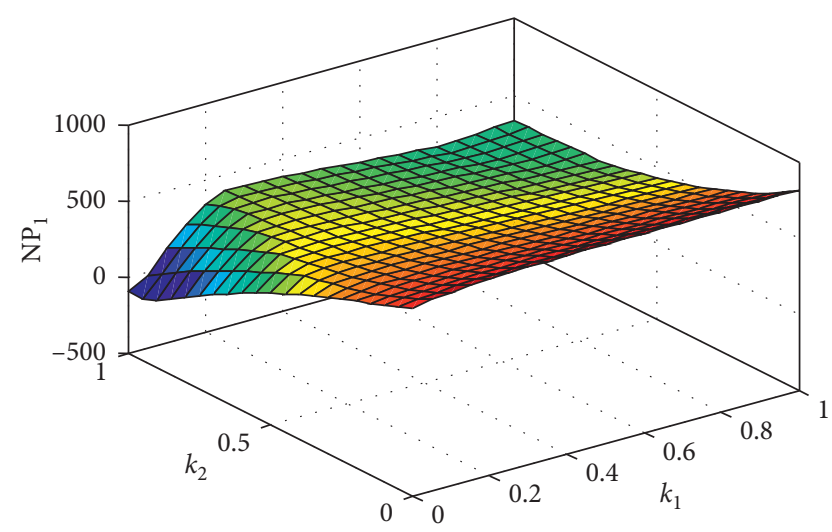

FIGURE 6: Relationship between the design enterprise's profit $\mathrm{NP}_{1}$ and the fairness concern behavior of both parties.

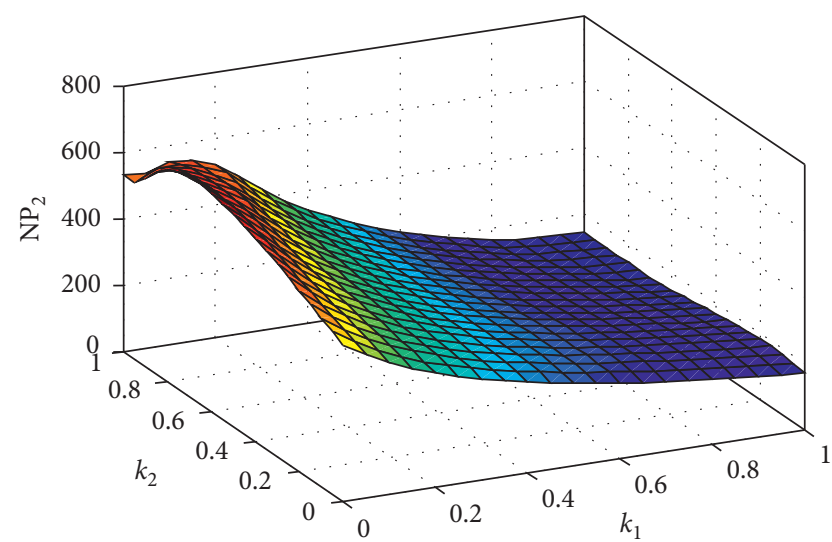

FIGURE 7: Relationship between the construction enterprise's profit $\mathrm{NP}_{2}$ and the fairness concern behavior of both parties.

utilization of the advantages of the EPC project. This study considers input, contribution, and fairness concern behaviors of both parties in the project optimization process, to build the profit sharing model of the EPC project optimization on the basis of game theory. From the perspective of maximizing the project optimization profit, the optimal profit sharing coefficient is determined; thus, the profit sharing mechanism of the EPC project is established. Moreover, the effect of the fairness concern behavior of both parties on the EPC project optimization and its profit sharing is further analyzed by simulation analysis.

This research makes three contributions. Firstly, the fairness concern of design and construction parties has a certain effect on their efforts, the profit sharing coefficient, the total project optimization profit, and the net profit that they can obtain. Secondly, when the other party has a certain fairness concern degree, its profit will increase with the increase of its own fairness concern degree. However, at the same time, the total project optimization profit will also decrease. Thirdly, when both parties have excessively high concerns about fairness, the profit sharing of project optimization is difficult to achieve. Therefore, the fairness concern degree of the design and construction companies should not be too high. The research results can provide support for the establishment of the EPC project revenue sharing mechanism and contribute to the application and sustainable development of the EPC model in the field of construction.

The profit distribution will be affected by the risk attitude of both parties. This study fails to consider the impact of the risk attitude of both parties on the profit distribution of EPC projects, which will be a future research direction of the authors. In addition, the values of some parameters in the model established in this paper need further evaluation. The methods of parameters evaluation have not been studied in this paper, which is also a direction for the future research.

\section{Data Availability}

The data used to support the findings of this study are available from the corresponding author upon request.

\section{Conflicts of Interest}

The authors declare that there are no conflicts of interest regarding the publication of this paper.

\section{Acknowledgments}

The authors acknowledge with gratitude the MOE (Ministry of Education in China) Project of Humanities and Social Sciences (No. 19YJC630078), National Key R\&D Program of China (No. 2018YFC0406905), Youth Talents Teachers Scheme of Henan Province Universities (No. 2018GGJS080), the National Natural Science Foundation of China (Nos. 71974056 and 71302191), the Foundation for Distinguished Young Talents in Higher Education of Henan (Humanities \& Social Sciences), China (No. 2017-cxrc-023), China Scholarship Council (No. 201908410388), China Scholarship Council (No.201908410388), and 2018 Henan Province Water Conservancy Science and Technology Project (GG201828). This study would not have been possible without their financial support.

\section{References}

[1] R. Pal, P. Wang, and X. Liang, "The critical factors in managing relationships in international engineering, procurement, and construction (IEPC) projects of Chinese organizations," International Journal of Project Management, vol. 35, no. 7, pp. 1225-1237, 2017.

[2] J. Ding, C. Chen, X. An, N. Wang, W. Zhai, and C. Jin, "Study on added-value sharing ratio of large EPC hydropower project based on target cost contract: a perspective from China," Sustainability, vol. 10, p. 3362, 2018.

[3] R. A. Perkins, "Sources of changes in design-build contracts for a governmental owner," Journal of Construction Engineering and Management, vol. 135, no. 7, pp. 588-593, 2009.

[4] G. Culp, "Alternative project delivery methods for water and wastewater projects: do they save time and money?" Leadership and Management in Engineering, vol. 11, no. 3, pp. 231-240, 2011.

[5] F. Y. Yao, Y. Y. Ji, H. X. Li et al., "Evaluation of informatization performance of construction industrialization EPC 
enterprises in China," Advances in Civil Engineering, vol. 2020, Article ID 1314586, 18 pages, 2020.

[6] C. Y. Lee, H. Y. Chong, Q. Li et al., "Joint contract-function effects on BIM-enabled EPC project performance," Journal of Construction Engineering \& Management, vol. 146, no. 3, Article ID 04020008, 2020.

[7] Y. Q. Niu, "Research on risk sharing and project distribution of the EPC general contracting project," Doctoral thesis, Nanjing University of Aeronautics and Astronautics, Nanjing, China, 2014.

[8] J. Y. Ding, N. Wang, and L. C. Hu, "Framework for designing project delivery and contract strategy in Chinese construction industry based on value-added analysis," Advances in Civil Engineering, vol. 2018, Article ID 5810357, 14 pages, 2018.

[9] L. Du, W. Tang, C. Liu et al., "Enhancing engineer-procureconstruct project performance by partnering in international markets: perspective from Chinese construction companies," International Journal of Project Management, vol. 34, no. 1, pp. 30-43, 2016.

[10] J. Y. Ding, Z. F. Wang, Y. M. X. Ling, and X. Q. Ren, "Innovation and key scientific issues of China's general contracting transaction model in water conservancy project," Journal of Economics and Water Resources, vol. 34, no. 5, pp. 33-37, 2016, in Chinese.

[11] P. Xiang and X. Niu, "Lessons of the failure of EPC projects implemented by Chinese foreign engineering contractors: a case study on the project of A2 highway in Poland," International Economic Cooperation, vol. 5, pp. 24-29, 2012.

[12] P. Xiang and Z. Wan, "Overseas EPC projects risk management of Chinese contractors: a case study of Mecca light railway project," International Economic Cooperation, vol. 6, pp. 52-55, 2011.

[13] N. Parrod, C. Thierry, H. Fargier et al., "Cooperative subcontracting relationship within a project supply chain: a simulation approach," Simulation Modelling Practice and Theory, vol. 15, no. 2, pp. 137-152, 2007.

[14] B. H. Guan and P. Hu, "Profit distribution mechanism of general project contractor of alliance," Systems Engineering, vol. 26, no. 11, pp. 94-97, 2008, in Chinese.

[15] Y. Zhang, P. Lv, and Y. Q. Song, "A study on profit distribution model of general contracting construction supply chain," Chinese Journal of Management Science, vol. 19, no. 4, pp. 98-104, 2011, in Chinese.

[16] P. Lv, Y. Zhang, and F. F. Mu, "Study on profit distribution of general contractor and subcontractor in construction supply chain- based modified Shapley value," Operational Research Management Science, vol. 21, no. 6, pp. 211-216, 2012, in Chinese.

[17] J. Wang and H. Q. Zhang, "Profit distribution model based on the Shapley value considering the risk under the EPC model," Journal of Civil Engineering and Management, vol. 33, no. 2, pp. 110-117, 2016, in Chinese.

[18] X. W. An, Z. F. Wang, J. Y. Ding et al., "Negotiation model of union general contracting project optimization profit distribution," Systems Engineering-Theory \& Practice, vol. 38, no. 5, pp. 1183-1192, 2018, in Chinese.

[19] E. Fehr and K. M. Schmidt, "A theory of fairness, competition, and cooperation," The Quarterly Journal of Economics, vol. 114 , no. 3, pp. 817-868, 1999.

[20] D. Kahneman, J. L. Knetsch, and R. Thaler, "Fairness as a constraint on profit seeking: entitlements in the market," The American Economic Review, vol. 76, no. 4, pp. 728-741, 1986.
[21] B. J. Ruffle, "More is better, but fair is fair: tipping in dictator and ultimatum games," Games and Economic Behavior, vol. 23, no. 2, pp. 247-265, 1998.

[22] C. H. Loch and Y. Wu, "Social preferences and supply chain performance: an experimental study," Management Science, vol. 54, no. 11, pp. 1835-1849, 2008.

[23] O. C. Demirag, F. Chen, and J. B. Li, "Coordinating a twostage supply chain with nonlinear demand and fairness concerns," European Journal of Operational Research, vol. 207, no. 3, pp. 1321-1326, 2010.

[24] E. Katok and V. Pavlov, "Fairness in supply chain contracts: a laboratory study," Journal of Operations Management, vol. 31, no. 3, pp. 129-137, 2013.

[25] J. Górecki and J. Bizon-Górecka, "Risk management in construction project: taking fairness into account," IOP Conference Series: Materials Science and Engineering, vol. 245, Article ID 072024, 2017.

[26] J. Bizon-Górecka and J. Górecki, "Influence of selected stakeholders of construction investment projects on the course of project," IOP Conference Series: Materials Science and Engineering, vol. 245, Article ID 072018, 2017.

[27] X. W. An, H. M. Li, O. Ojuri et al., "Negotiation model of design optimization profit distribution with fairness concerns in construction projects," KSCE Journal of Civil Engineering, vol. 22, no. 7, pp. 2178-2187, 2018.

[28] Q. Fu and H. Zhu, "Incentive mechanisms based on fairness preference theory-give consideration to both vertical and horizontal fairness concerns," Journal of Industrial Engineering and Management, vol. 28, no. 3, pp. 190-195, 2014, in Chinese.

[29] Y. Wang and J. Liu, "Evaluation of the excess profit sharing ratio in PPP projects using principal-agent models," International Journal of Project Management, vol. 33, no. 6, pp. 1317-1324, 2015. 